\title{
A 7-level inverter with less number of switches for grid-tied PV applications
}

\author{
J. N. Bhanute $\mathbf{j}^{12^{*}}$ and Rani Chinnappa Naidu ${ }^{1}$ \\ School of Electrical Engineering, Vellore Institute of Technology, India ${ }^{1}$ \\ Department of EEE, Vignana Bharathi Institute of Technology, Hyderabad, India ${ }^{2}$
}

Received: 17-April-2021; Revised: 28-May-2021; Accepted: 29-May-2021

(C)2021 J. N. Bhanutej and Rani Chinnappa Naidu. This is an open access article distributed under the Creative Commons Attribution (CC BY) License, which permits unrestricted use, distribution, and reproduction in any medium, provided the original work is properly cited.

\begin{abstract}
Abs tract
In the current context, Medium Voltage High Power (MVHP) applications are developing industrial technologies. The direct connection of a Photovoltaic (PV) system to an MVHP system may cause various connectivity challenges. To address the interconnection difficulties, this paper describes a 7-Level Cascaded H-Bridge Multilevel Inverter (CHB-MLI) architecture with fewer switches and lower harmonics. This article proposes the Reduced Switch Multilevel Inverter (RSMLI). This design is less expensive than traditional Multilevel Inverter (MLI) topologies, and it is ideally suited for medium voltage and high-power applications since it synthesizes numerous Direct Current (DC) sources. The innovative 7-Level inverter is represented with a decreased number of switches using the Phase Opposition Disposition (POD) methodology. The lower switch count helps the construction of simple converter structures. To boost performance, the MATLAB/Simulink results are evaluated.

Keywords

Multilevel inverter (MLI), Pulse width modulation (PWM), Phase opposition disposition (POD), Photovoltaic (PV) systems, Reduced switch components (RSC), Total harmonic distortion (THD).
\end{abstract}

\section{Introduction}

Because of the massive power demand and fast increase of industrial needs, traditional power production is falling behind. The negative impacts of conventional power production have pushed technology toward renewable energy sources, with solar power being an ample supply for current and future demands [1]. Medium voltage grid utility applications need the use of medium voltage and megawatt power levels. Stand-alone renewable energy systems, particularly Photovoltaic (PV) systems with micro grid and uninterruptible power supply systems, need output voltages with excellent power quality characteristics, such as low total harmonic distortion and quick dynamic response [2]. The primary issue here is the control approach for the Direct Current (DC) -DC converter and the DC-AC inverter. This issue is solved via Multiple Maximum Power Point Tracking (MPPT) and Cascaded H-bridge (CHB) algorithms and topology. In this context, the Multilevel Inverter (MLI) plays an important role in converting DC to Alternating Current (AC), with the number of levels, determining the realisation of pure sinusoidal voltage output [3-4].

*Author for correspondence

631
As the level of the inverter grows, the Total Harmonic Distortion (THD) decreases, but the number of switches for the inverter grows by. The increasing switches subsequently enhance the complexity of the inverters, thus the greater the number of levels, the more switches. Reduced switch Multilevel Inverter (RSMLI) [5] will solve the issue of additional switches. In this study, an A7-level inverter with fewer switches is investigated in order to achieve reduced THD and higher levels; it employs less switches than a standard inverter. Although obtaining a clean sinusoidal wave from inverters is nearly impossible owing to a variety of reasons. MLI utilised for DC-AC conversion in high power medium voltage applications is classified as follows [6].

1) Neutral-Clamped Inverters

2) Capacitor-Clamped Inverters

3) Cascaded H-bride Inverters

Because a solar PV system is made up of numerous PV panels, the output voltage of each panel may not be constant and may fluctuate depending on irradiance and meteorological conditions. So, in addition to the neutral clamped and the capacitor clamped inverters, the cascaded H-bridge inverter was selected for the design of the 7-level inverter. Because the cascaded $\mathrm{H}$ - 
bridge inverter may be powered by several alternating current sources.

The work is intended:

- To simulate a 7-level inverter for photovoltaic systems using a RSMLI.

- To compare modulation index values at various levels $(\mathrm{Ma}>1, \mathrm{Ma}=1, \mathrm{Ma}<1)$.

- To determine the benefits and limitations, compare its performance to that of an existing converter with RSMLI architecture.

- To investigate and compare THD with R-Load and RL-Load.

\section{Literature review}

Bana et al. [7] provided an overview of reduced switch multilevel inverters and their potential applications in the industry. It compares several features of the RS MLI system, such as switching methodology, controller type, difficulties, and present situation. According to the report, new reduced switch multilevel inverter topologies provide a variety of benefits such as lower cost, lower losses, and smaller space.

Panda et al. [8] A design of Switched Diode Dual Source Single Switch (SDDS) MLI was suggested. The basic goal is to provide the greatest number of outputs while employing the fewest number of switches. The suggested system was compared to ten different systems, and the suggested system had the lowest power loss in the low power range. Also presented a new modified fish swarm optimization (FSO) algorithm that uses the PSO method to reformulate FSO, resulting in a reduction in step values. It outperforms other methods in terms of fitness function minimization. The SDDS MLI is helpful for producing higher level output voltage with fewer switches.

Siddique et al. [9] developed a unique architecture with the goal of achieving greater output levels with fewer switches and a lower total standing voltage. The system generates 13 levels of output using eight unidirectional switches and three DC sources. For the suggested topology, three alternative sorts of extensions are made accessible. In comparis on to previous topologies, the suggested topology needs fewer gate driver circuits. A comparison and power loss study have been performed. As a consequence, the topology has a fundamental unit efficiency of $98.5 \%$.

Omer et al. [10] provide a comprehensive overview of some of the most recently suggested multilevel inverter topologies in several areas. It includes both traditional and freshly suggested topologies. Topologies are reviewed in terms of many factors such as decreased switch count and number of DC sources. It also includes terminology and evaluation criteria. 16 new suggested topologies are chosen, and their comparison, benefits, and disadvantages are provided.

Hosseinpour et al. [11] developed a unique construction for multilayer inverters based on switching diode source cells. It offers bidirectional feeding, inexpensive switch costs, and a low overall blocking voltage. The benefit of this construction is that it only takes one switch diode source cell to enhance the output by two levels. Different parameters have been compared. It features fewer switching losses, fewer switches, and fewer gate driver circuits, resulting in a lower overall cost and a smaller overall system footprint.

Mondol et al. [12] investigated a concept for a novel three-phase multilevel inverter powered by a single energy storage or battery. The staircase modulation approach is used to create switching signals. This architecture features reduced switching losses, allowing the inverter to run at a low switching frequency while maintaining optimum output current harmonic distortion. Finally, since the Total Standing Voltage (TSV) reduces voltage and current levels, the cost of the components is reduced.

Kakar et al. [13] suggested a single phase MLI architecture to minimize the switch count. This architecture has four DC inputs, one bidirectional power switch, and eight unidirectional power switches. The power switches control the higher voltage applications. In the switching strategy, the nearest level is to be utilized.

Srinivasan et al. [14] conducted a thorough study on the decreased switch count for multilayer inverters. A switched ladder inverter may provide 81 different output voltage levels. By raising the magnitude of the DC sources, the number of output levels may be increased. Observe a single-phase induction motor speed with regard to change in load torque when an 81-level inverter is attached.

Singh et al. [15] of a grid-connected Photovoltaic (PV) system with a multilayer inverter. Under continually charged weather circumstances, the Proportional Integral (PI) current regulated algorithm is utilized to calculate Unity Power Factor (UPF). The generated 
grid current is sinusoidal, and the PI controller provides an excellent dynamic response.

Sandhu and Thakur [16] demonstrated a hybrid energy system with a 17-level inverter. They demonstrated a model that generates seventeen levels of output by lowering switch count, resulting in greater efficiency and lower THD compared to 9 and 13 levels. They created the model by employing ten Metal-OxideSemiconductor Field-Effect Transistor (MOSFET) switches. This artificial neural network (ANN) has been utilized to produce Pulse Width Modulation (PWM) pulses for the inverter. We can obtain a rapid Maximum Power Point (MPP) by utilizing the Artificial Neural Network -Photovoltaics (ANN-PV) technique.

According to Narasimhulu et al. [17], a shunt active power filter adjusts for load current harmonics by injecting harmonic compensating current. The fuzzy logic control is recommended for controlling Shunt Active Power Filter (SAPF). Since it has more control capability. The suggested PI and Fuzzy Logic Controller (FLC) is using Alternate Phase Opposition Disposition (APOD), Phase Opposition Disposition (POD), and Phase Disposition (PD) triangular carriers results in lower THD and higher power factor. We can perform reactive power adjustment utilising the suggested computational intelligence-based controller.

Rajalakshmi and Rangarajan [18] suggested a modified three-phase nine-level multilevel inverter scheme. The number of switches in the multilayer inverter will be lowered by employing this architecture. For symmetrical and asymmetrical DC sources, the suggested topology outperforms the Alternate Phase Opposition Disposition Pulse Width Modulation (APOD-PWM) approach in terms of THD.

Researchers Rana et al. [19] observed that the flying capacitor type multilevel inverter has little benefits over the Diode Clamped Multilevel Inverter (DCMLI) and Cascaded H-bridge Multilevel Inverter (CHBMLI). Increase in voltage between two neighboring electrical drives in Flying Capacitor Multilevel Inverter (FCMLI). The FCMLI is used to decrease switching losses. For balancing the voltage levels of capacitors, phase redundancies are offered in FCMLI.

The Single-Phase Transformer Less Grid-Connected Photovoltaic (SPTG-CPV) inverters are being reviewed by Zeb et al. [20] Loss analysis for different grid configurations at $1 \mathrm{~kW}$, connected transformerless inverter topologies are described. The operational principles of all SPTG-CPV inverters are explained in detail for positive, negative, and zero cycles. AC side decoupled topologies such as Highly Efficiency and Reliable Inverter Concept (HERIC), REFU, and Full Bridge Zero Voltage Rectifier (FBZVR) have more efficiency than DC side decoupled topologies such as H5, Full-Bridge Inverter with DC Bypass (FB-DCBP).

\section{Materials and methods a) System Description}

The parts that follow go through the traditional 7-level inverter, the modified 7-level CHB-MLI with reduced switch operation, and total harmonic distortion for 7level inverters. Sections 4 and 5 offer the POD methodology and Simulink models, respectively, while section 6 presents the outcomes and section 7 discusses data analysis and comments.

\section{b) Conventional seven level multilevel inverter topology}

The objective of traditional Cascade Multilevel Inverters is to link H-bridges in series with separate DC voltage sources. In MLI, a staircase output voltage (or) current waveform is created by connecting many power semiconductor devices, i.e., Insulated Gate Bipolar Transistors (IGBTs) in cascaded mode with distinct DC sources. Because all DC sources in a symmetrical MLI topology are equivalent to Vdc, we consider existing MLI to be a symmetrical topology. For a seven-level cascaded MLI is made up of three Hbridges and three voltage sources. Every switch in the topology necessitates the use of a gate driver circuit. The number of inverter levels is determined by the switches utilised. A total of 12 switches is employed in this architecture. Each H-bridge is powered by a single DC voltage source. Here output voltages are +3Vdc, +2Vdc, +Vdc, 0, - Vdc, -2Vdc, -3Vdc [21]. The output voltage in terms of the H-bridges equation is given by

$V o=2 k+1$

Where $\mathrm{k}$ is the number of $\mathrm{H}$-bridges.

Number of output voltage levels in terms of a power semiconductor device [22]

$V o=\frac{m+2}{2}$

Where $\mathrm{m}$ denotes Power semiconductor devices. The Figure 1 shows the conventional 7-Level CHB inverter.

Figure 2 shows a block diagram of a reduced switch MLI using a PWM approach for grid-connected PV 
applications. The cascade multilevel inverter in this architecture is made up of nine IGBT switches and three DC Sources. Five of the nine switches are separate, with the remaining switches stacked in a cascade fashion to provide positive and negative polarities of output voltage. A higher number of voltage sources in a topology results in more steps in the output waveform, which improves the sinusoidal wave with a better harmonic spectrum, reduced power losses, and more accuracy at load.

\section{c) Modified 7-Level CHB-MLI with reduced s witches}

The greatest output voltage that the 7-Level Inverter can generate is $3 \mathrm{Vdc}$, and switches S5, S6, and S8 are all turned on. Similarly, the ON State status of switches at different levels is illustrated in Table 1. Every switch in a topology necessitates the use of a gate driver circuit [23]. Figure 3 depicts the proposed cascaded MLI architecture, which comprises of nine switches. In contrast, a traditional cascade contains 12 switches. By comparing these two topologies, three switches are removed from the standard cascade MLI, resulting in a reduction in circuit complexity and total cost of the equipment module.

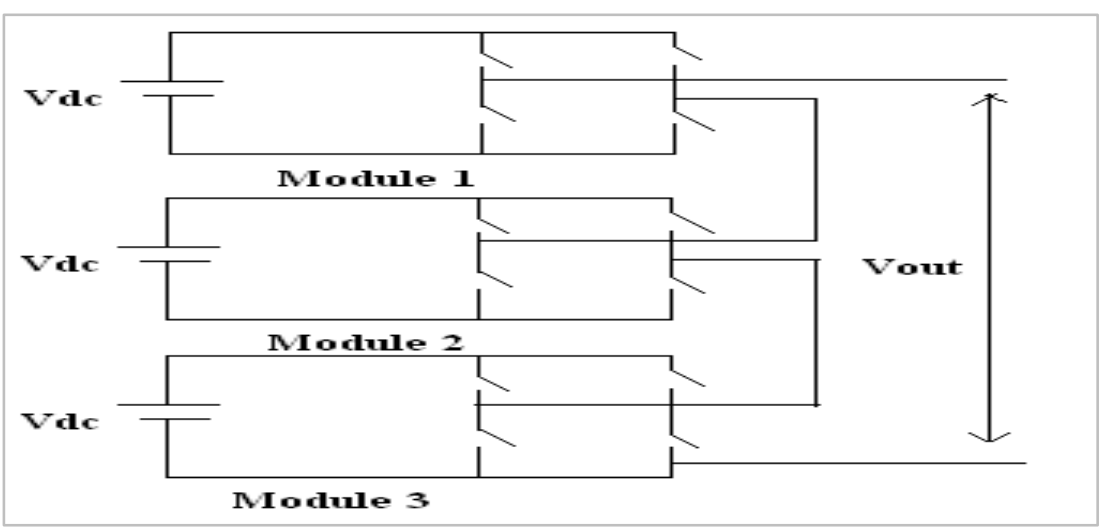

Figure 1 Conventional Seven level CHB inverter

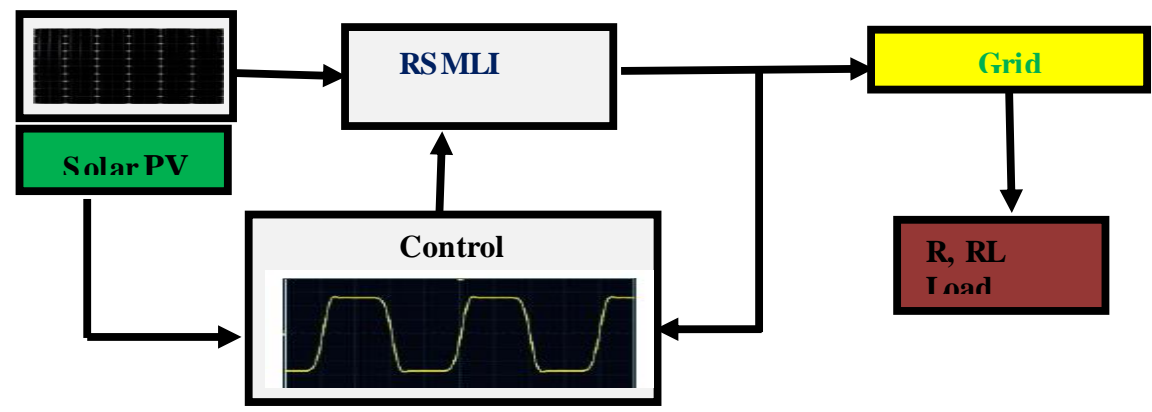

Figure 2 RSMLI with PWM control

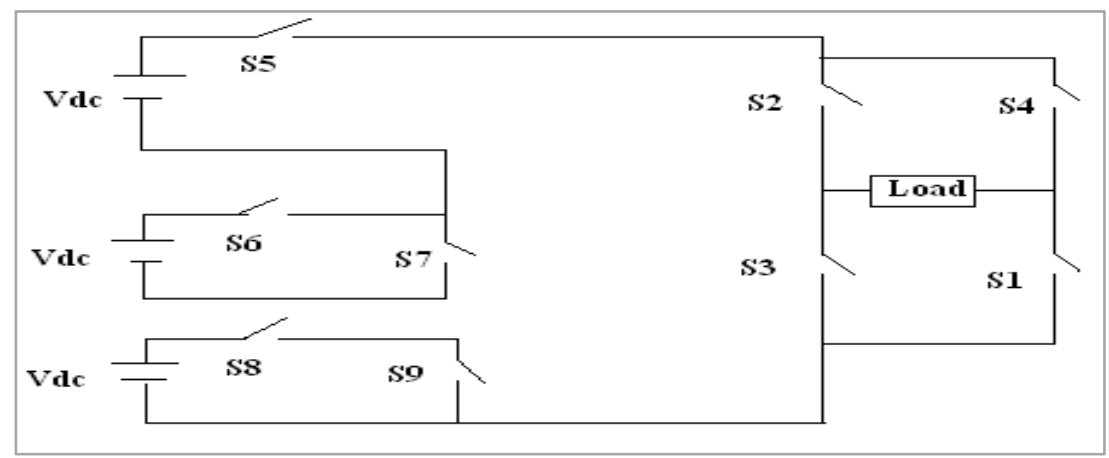

Figure 3 Modified seven level Inverter 634 
Table 1 Switching states of reduced 7-level inverter

\begin{tabular}{llllll}
\hline S witches/switching state & & & & Output voltage (Volts) \\
\cline { 1 - 4 } S5 & S6 & S7 & S8 & S9 & \\
\hline 1 & 0 & 1 & 0 & 1 & Vdc \\
\hline 1 & 1 & 0 & 0 & 1 & $2 \mathrm{Vdc}$ \\
\hline 1 & 1 & 0 & 1 & 0 & $3 \mathrm{Vdc}$ \\
\hline 0 & 0 & 0 & 0 & 0 & 0 \\
\hline 0 & 1 & 0 & 1 & 0 & $-\mathrm{Vdc}$ \\
\hline 0 & 0 & 1 & 1 & 0 & $-2 \mathrm{Vdc}$ \\
\hline 0 & 0 & 1 & 0 & 1 & $-3 \mathrm{Vdc}$ \\
\hline
\end{tabular}

\section{Phase opposition disposition technique}

Switches in an inverter change positions between two states to regulate the output voltage (i.e., ON, OFF). This procedure is repeated indefinitely by varying the width of the pulses [24]. The POD technique is used in this topology. It is a carrier-based modulation technique used to generate pulses for the proposed cascaded seven-level inverter. Carrier waveforms above the reference are in phase in the phase opposition disposition technique, whereas those below zero are 180 degrees out of phase. CHB-MLI needed six carrier waveforms for seven levels, which are comparable to the modulating sinusoidal signal of 50 $\mathrm{Hz}$ waveform [25]. The positive and negative polarity of pulses is created, and these pulses form the switching sequence of the inverter to get the required output voltage. The number of carrier waveforms $(\mathrm{T})$ equals $\mathrm{N}-1$, where $\mathrm{N}$ is the number of levels.

\section{Simulink models}

Figure 4 depicts a seven-level CHB-MLI constructed with nine IGBT switches. It has three DC voltage sources and a load resistance range of $10 \mathrm{~V}$ and $10 \Omega$. An LC-filter is attached to the Inverter output to reduce harmonics at the load end. For this topology, pulses are created using the POD approach, which compares six carrier waves with a frequency of $5 \mathrm{kHz}$ to modulated sinusoidal signals with a frequency of 50 Hz. Figure 5 shows the Simulink model of unequal pulse width technique. Figure 6 shows the Simulink model of phase opposition disposition method $(\mathrm{Ma}=1$, $\mathrm{Ma}<1)$.

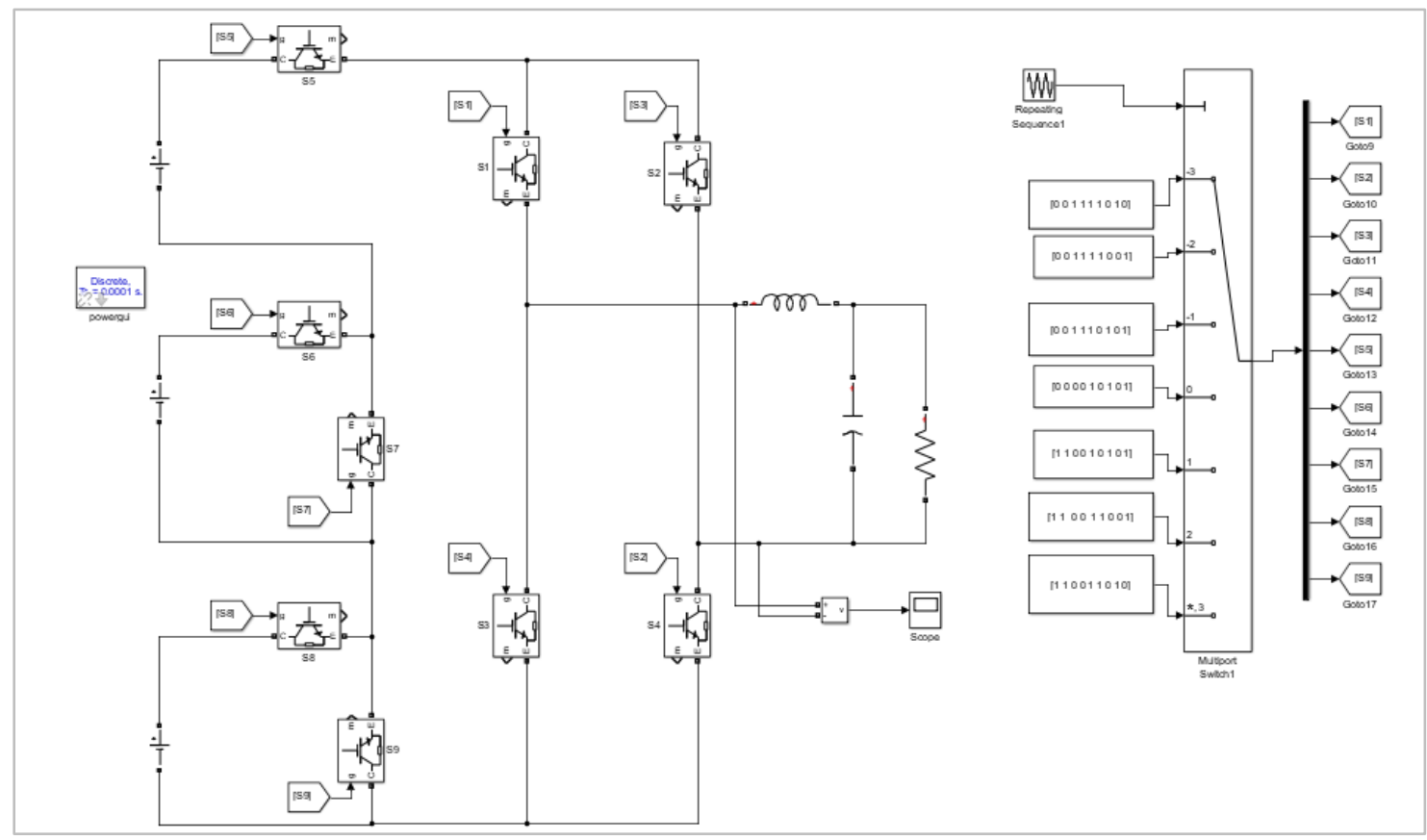

Figure 4 Simulink model of equal pulse width technique 
J. N. Bhanutej and Rani Chinnappa Naidu

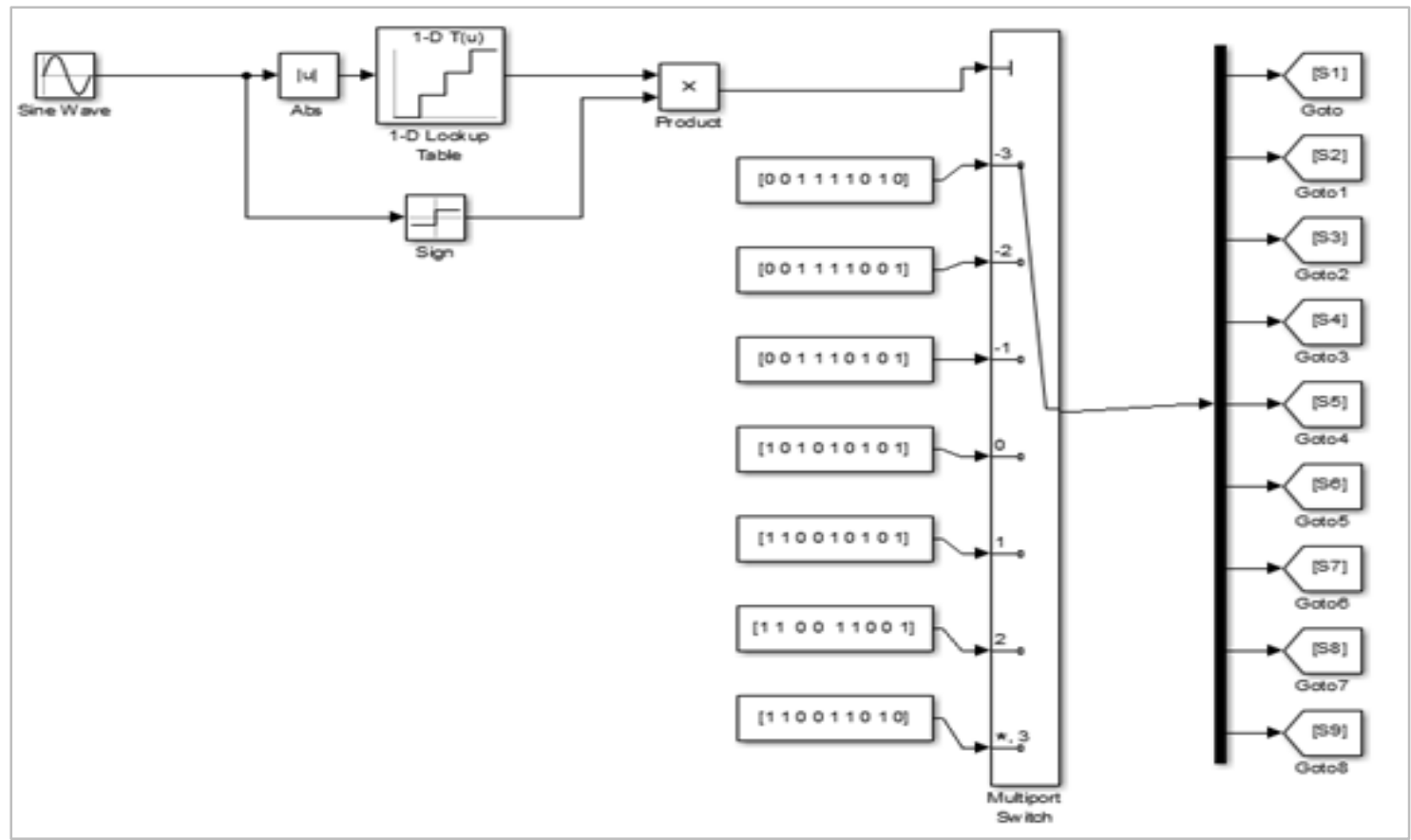

Figure 5 Simulink model of unequal pulse width technique

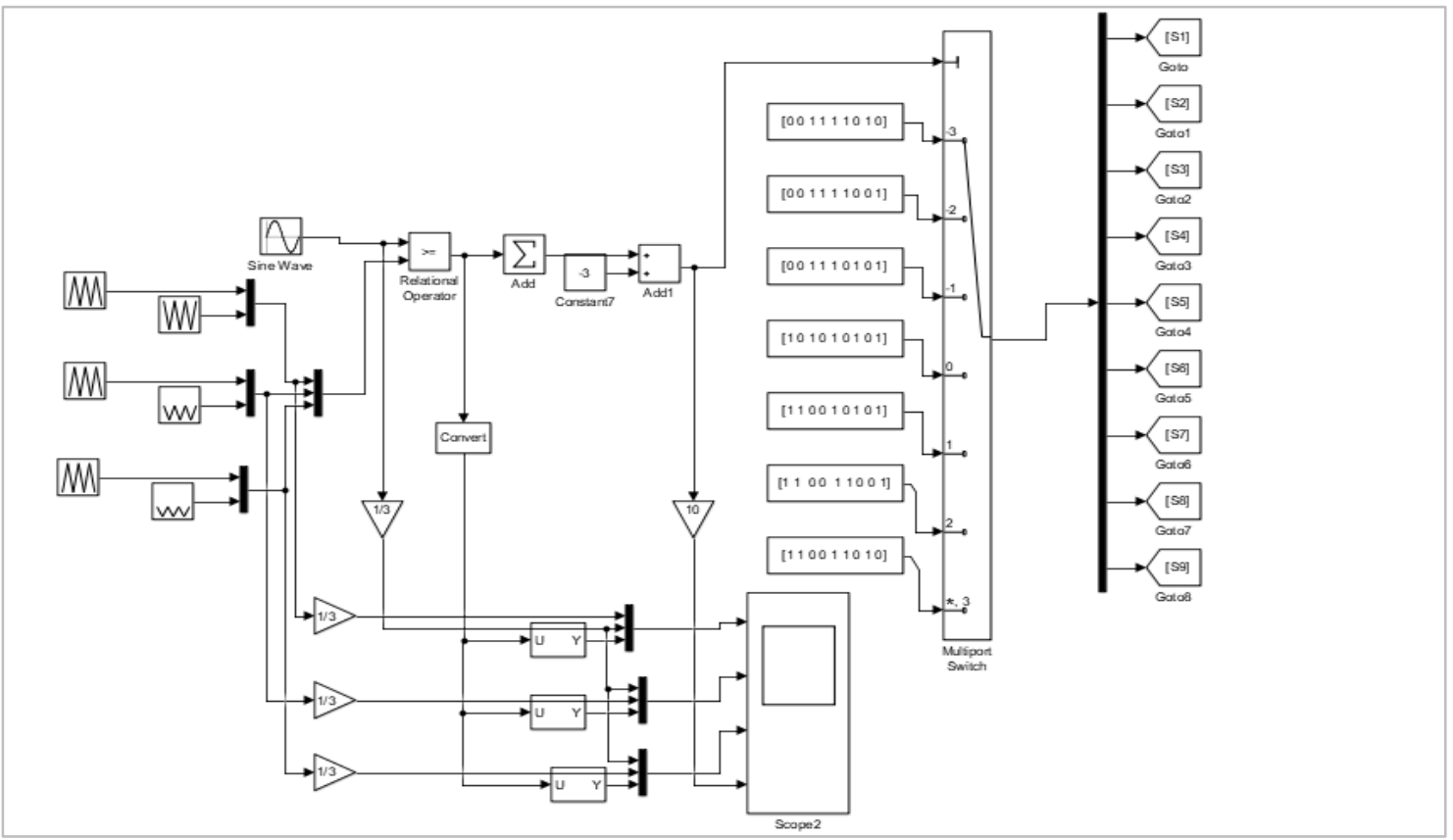

Figure 6 Simulink model of phase opposition disposition method $(\mathrm{Ma}=1, \mathrm{Ma}<1)$

\section{Results}

Figure 7 depicts the output THD of a conventional 7level inverter, whereas Figure 8 depicts the THD with reduced switch MLI caused by an uneven voltage source. PWM pulses are created by comparing a triangle wave to a fixed sinusoidal wave [26]. When compared to uneven PWM, equal pulse width has a larger level of THD. Figure 9 shows the Fast Fourier Transform (FFT) Analysis of unequal pulse width technique. In uneven pulse width modulation, third order harmonics are missing. Figure 10 depicts the output voltages of the Phase opposition disposition 
approach when the modulation index $(\mathrm{Ma}=1)$ is used. Pulse produced by comparing six triangular carrier waves at $5 \mathrm{kHz}$ to a fixed sinusoidal wave at $50 \mathrm{kHz}$. When the modulation index is equal to one using the multi carrier POD technique, higher order harmonics are created than before. Figure 11 depicts the outcome of the phase opposition disposition approach using modulation index $(\mathrm{Ma}<1)$, indicating that higher order harmonics are significantly decreased. Figure 12 shows the FFT analysis of phase opposition disposition technique $(\mathrm{Ma}<1)$. Figure 13 shows the FFT analysis of POD technique with filter $(\mathrm{L}=10 \mathrm{mH}$ and $\mathrm{C}=100 \mathrm{uF})$. Because the proportion of higher order harmonics is significant, LC filters are required for a modulation index of one.

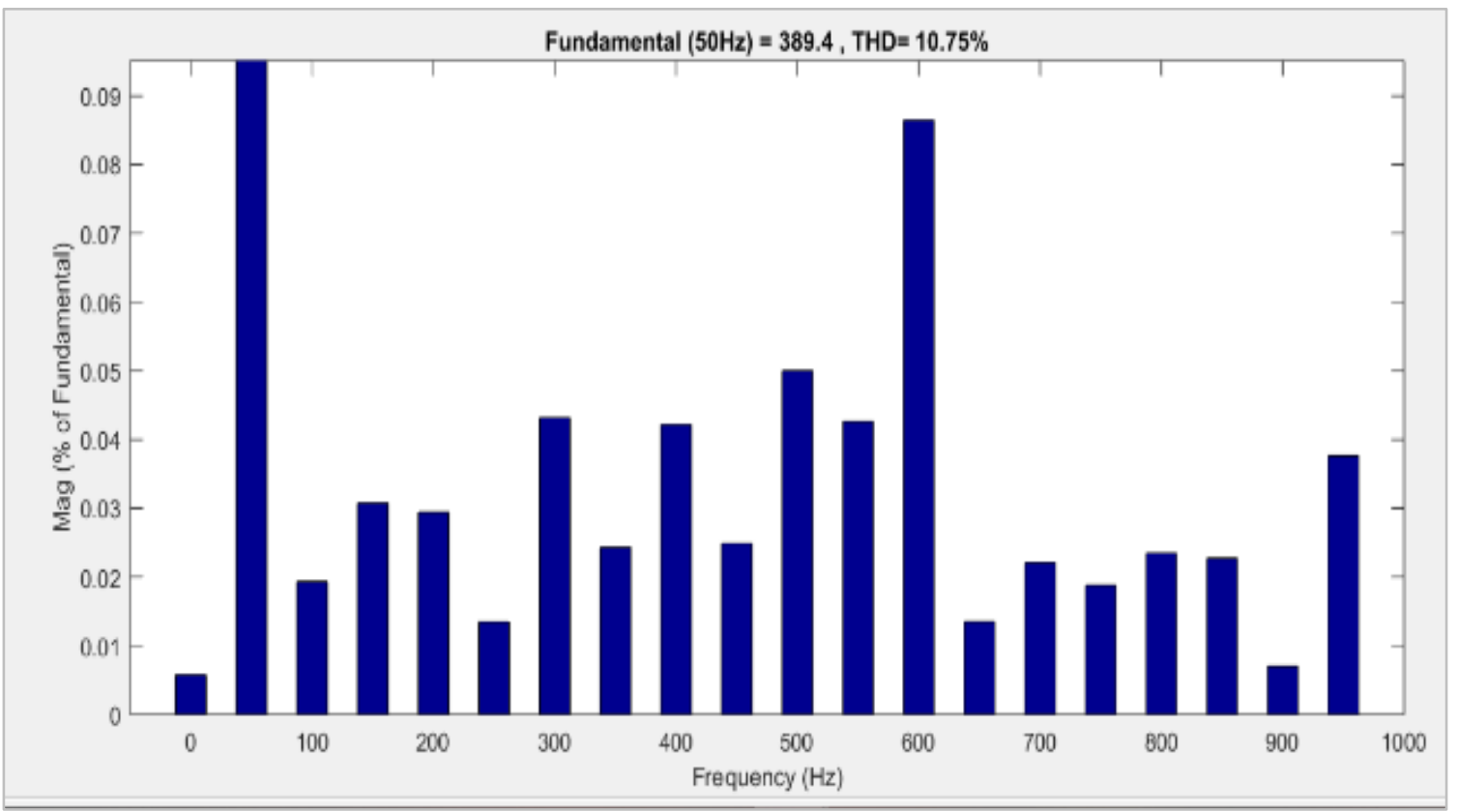

Figure 7 Conventional 7-level inverters: FFT analys is

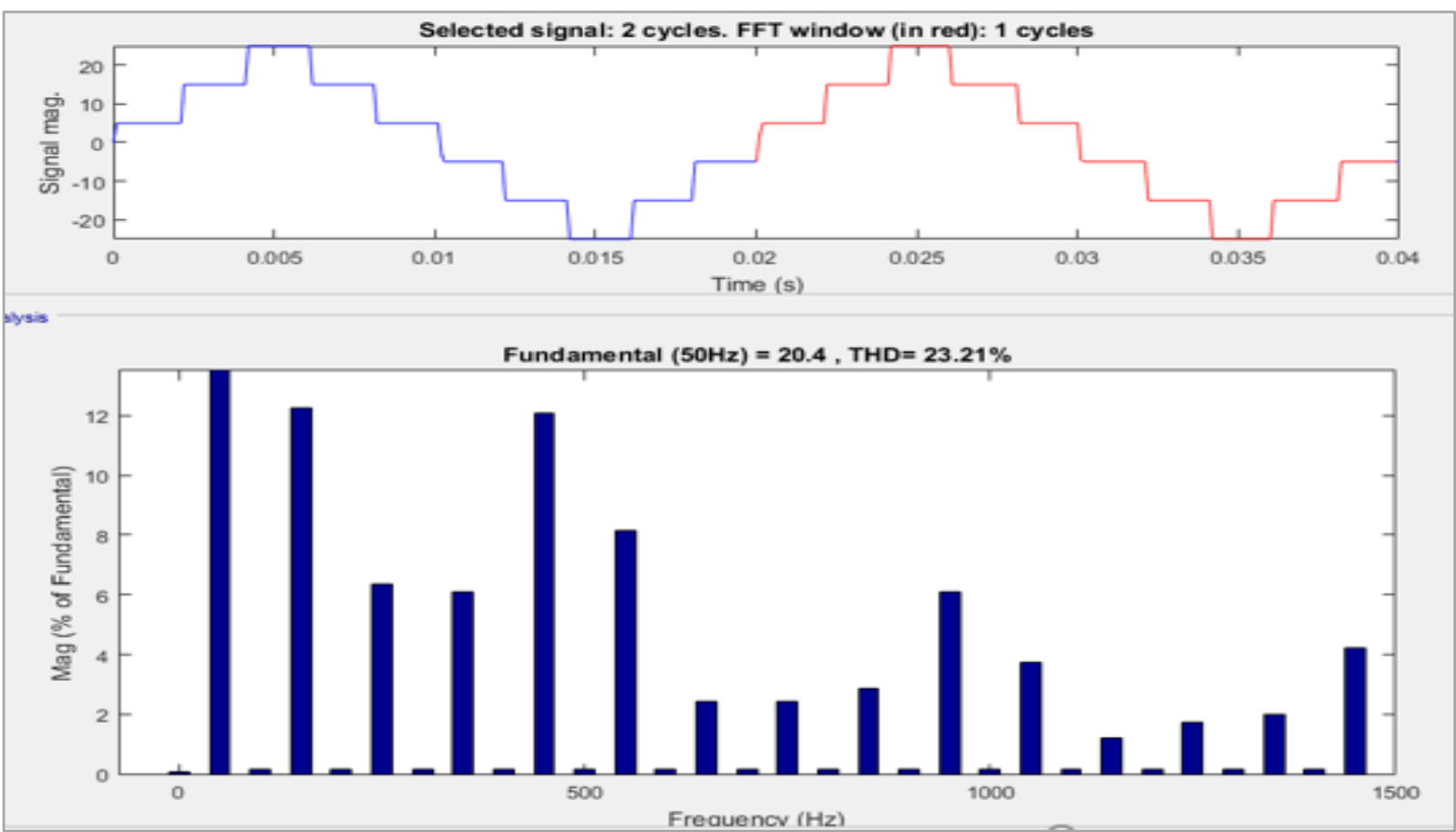

Figure 8 FFT Analysis of equal pulse width technique 
J. N. Bhanutej and Rani Chinnappa Naidu
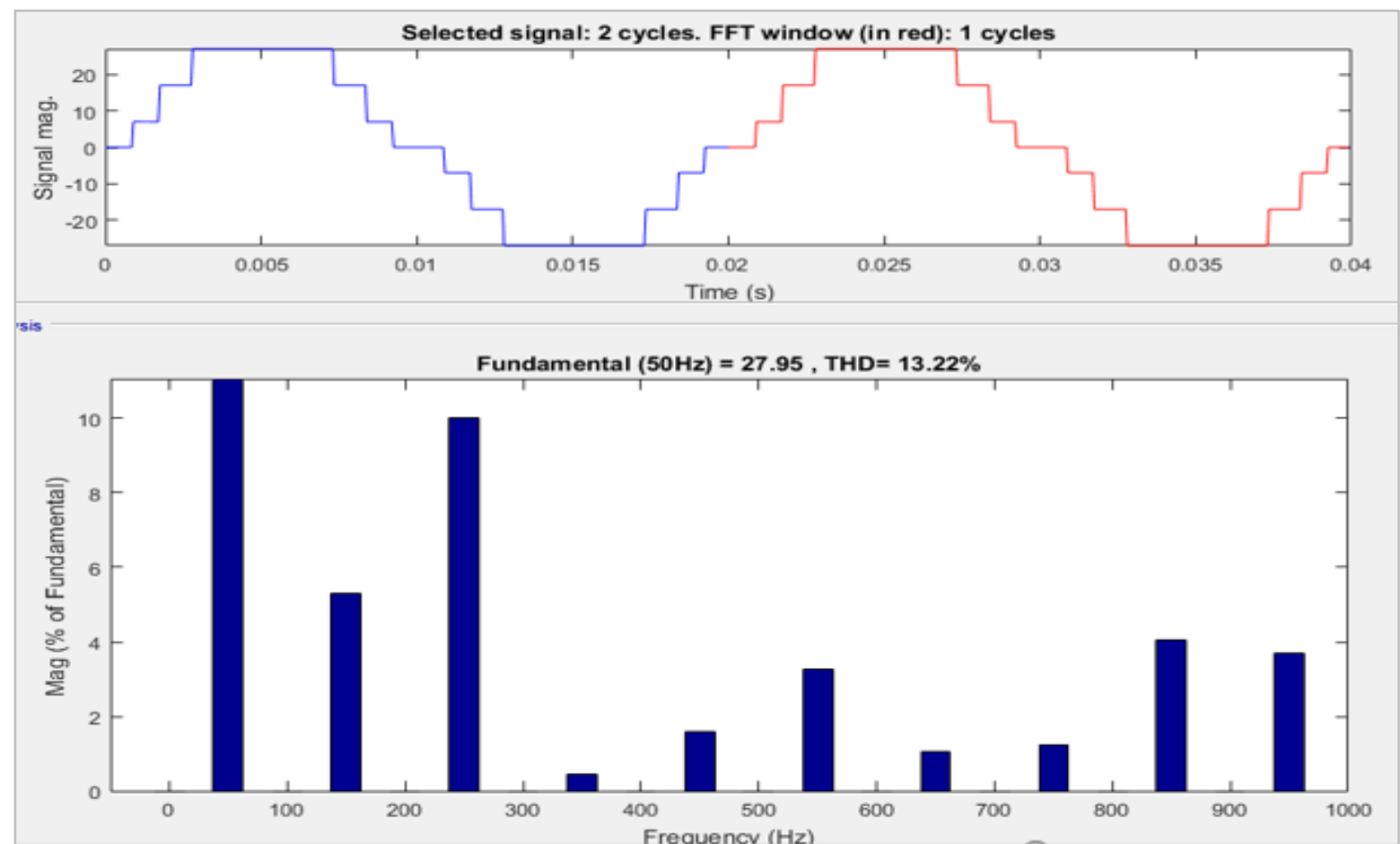

Figure 9 FFT Analysis of unequal pulse width technique

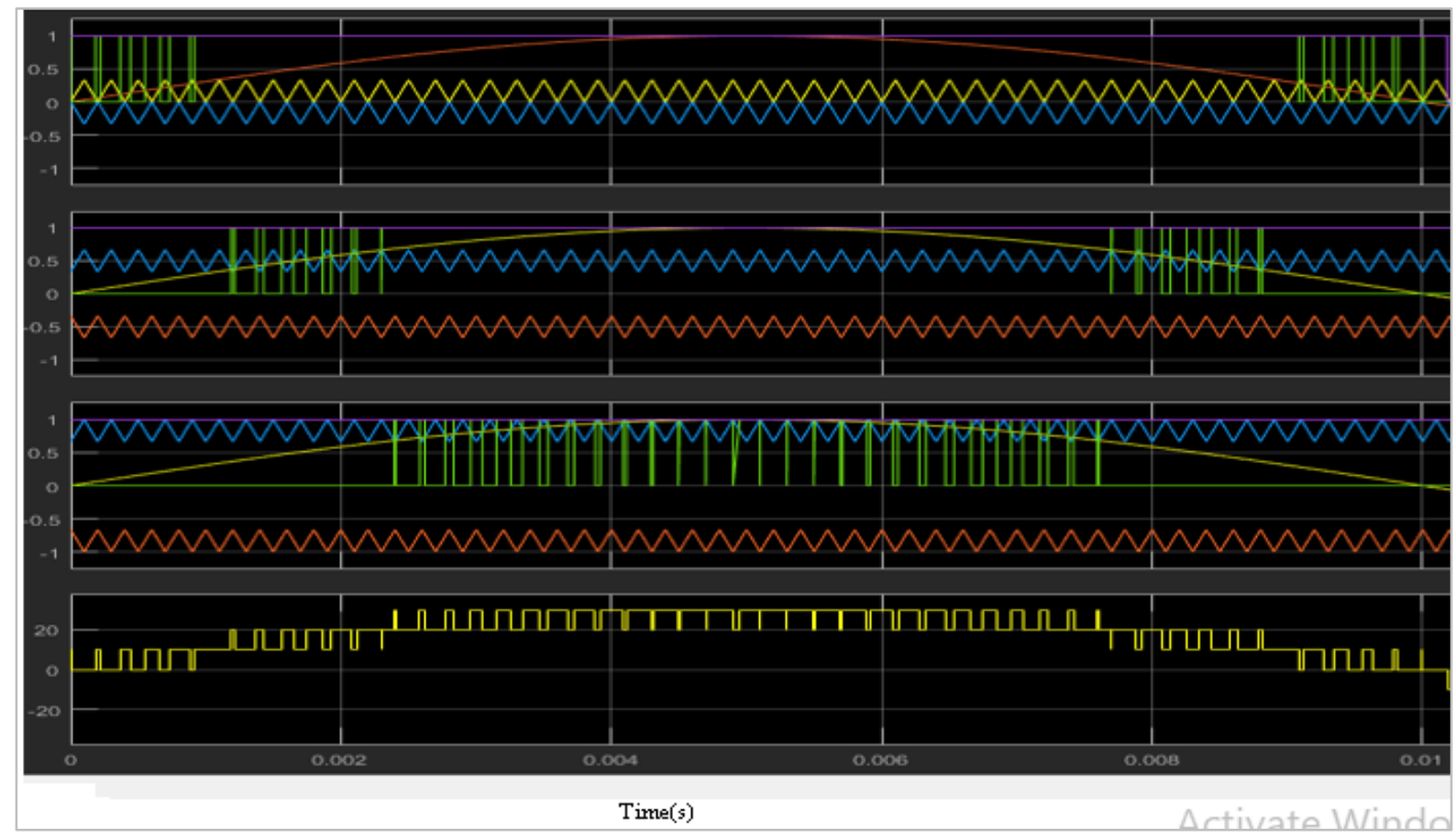

Figure 10 Output of POD multicarrier technique 
International Journal of Advanced Technology and Engineering Exploration, Vol 8(78)

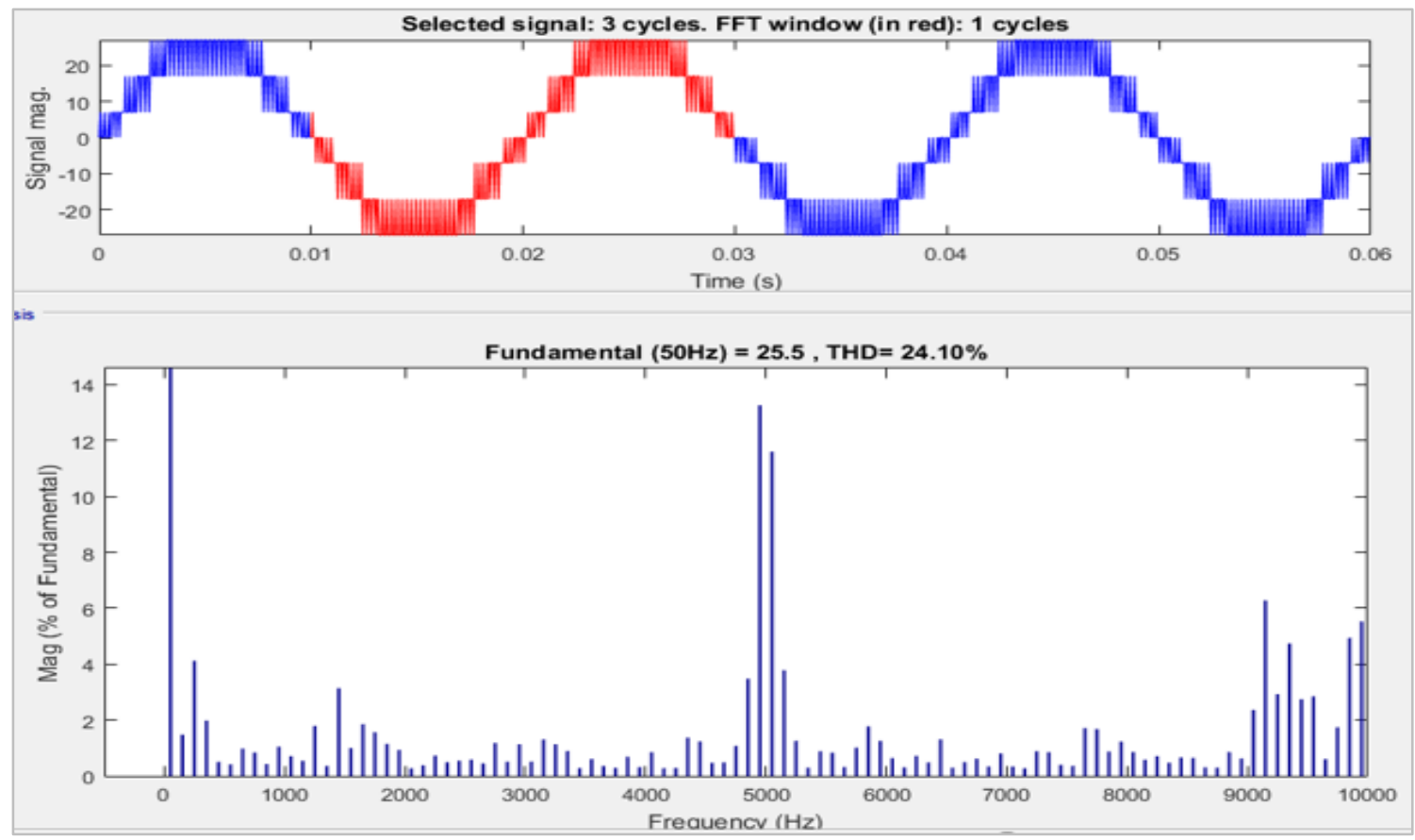

Figure 11 FFT Analys is of phase opposition disposition technique $(\mathrm{Ma}=1)$
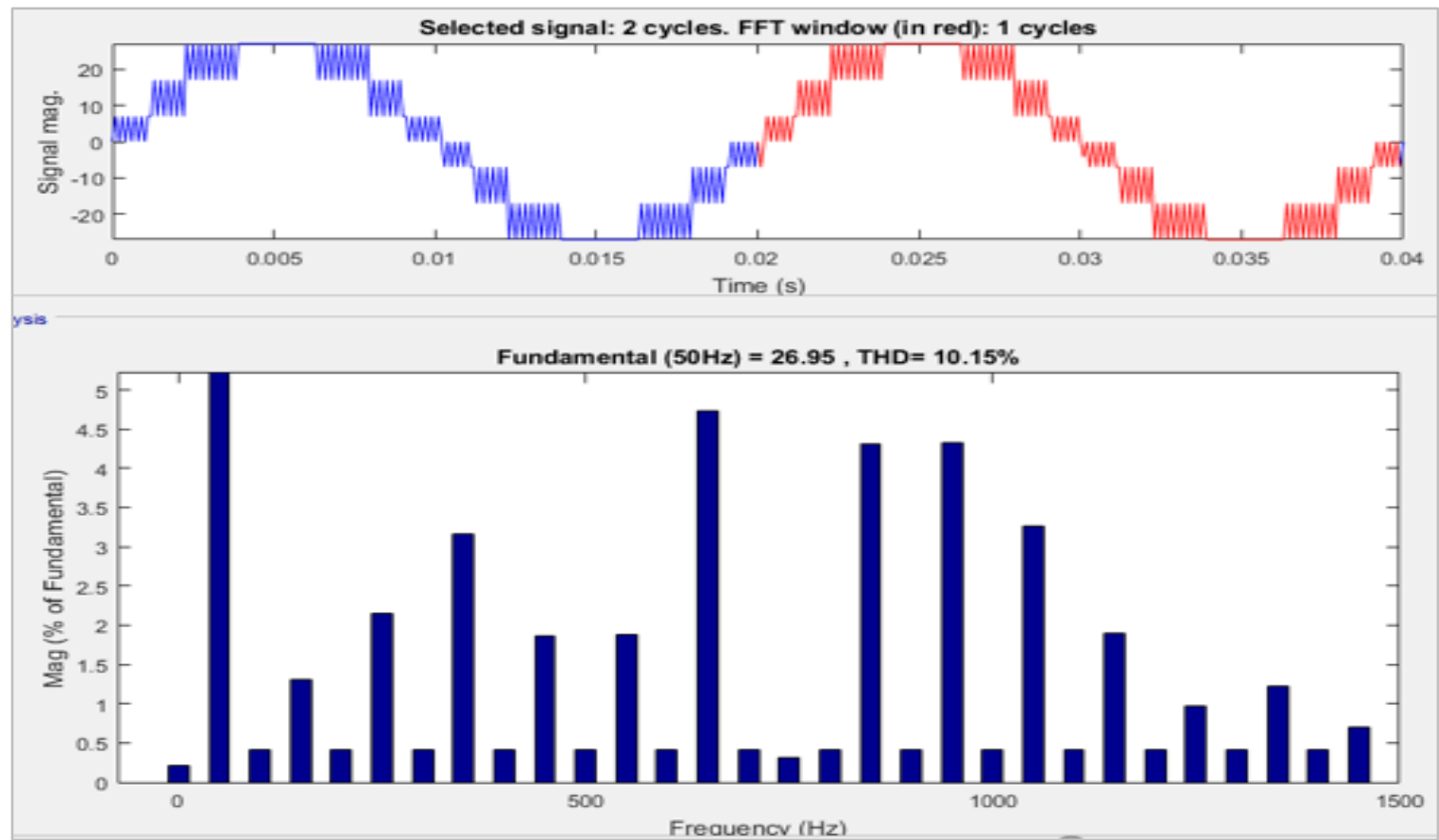

Figure 12 FFT analysis of phase opposition disposition technique (Ma<1) 


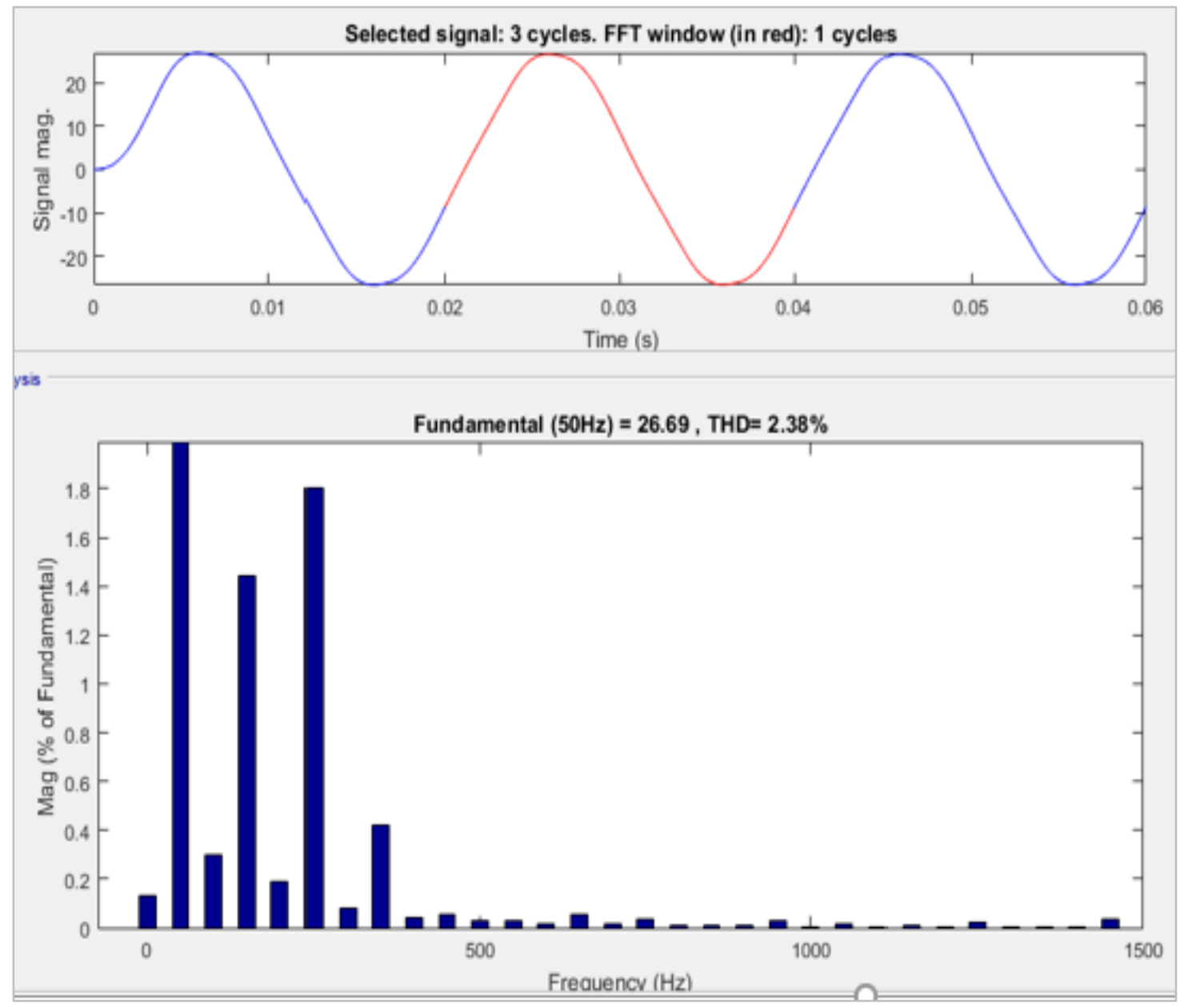

Figure 13 FFT analys is of POD technique with filter $(\mathrm{L}=10 \mathrm{mH}$ and $\mathrm{C}=100 \mathrm{uF})$

\section{Data analysis and discussions}

Table 2 compares different characteristics. In a capacitor clamped inverter, 14 capacitors and 10 switches are needed, but a diode clamped inverter requires 6 capacitors, 8 diodes, and 10 switches. The suggested RSMLI architecture reduces the number of switches to 9 and eliminates the need for capacitors and diodes. RSMLI architecture not only minimises the number of switches, but also the circuit complexity. Despite various benefits, the RSMLI suffers fromvoltage stress on switching devices, since the decrease in switches increases voltage stress on switching devices. This voltage stress issue may be avoided by adopting higher switch ratings that can endure voltage stress. Table 3 compares THD with and without filter, with a same pulse width with filter the THD value is $13.04 \%$ and without filter it is $23.21 \%$. The POD technique is used to analyse three modulation index values: $(\mathrm{Ma}=1),(\mathrm{Ma}<1)$ the associated THD values are $24.11 \%, 10.15 \%$, and $2.38 \%$, respectively.

Table 2 Comparis on of various parameters

\begin{tabular}{lllll}
\hline Parameter & Capacitor clamped & Diode clamped & $\begin{array}{l}\text { Conventional } \\
\text { cascaded H-bridge }\end{array}$ & Proposed topology \\
\hline No.of Capacitors & 14 & 6 & --- & -- \\
\hline No.of diodes & -- & $>8$ & --- & -- \\
\hline No. of switches & 10 & 10 & 12 & 9 \\
\hline
\end{tabular}


Table 3 Comparis on of total harmonic distortion

\begin{tabular}{|c|c|c|c|c|}
\hline \multirow[t]{2}{*}{ Sl. No. } & \multirow[t]{2}{*}{ Parameter } & \multicolumn{2}{|c|}{ Total Harmonic distortion (THD) } & \multirow{2}{*}{$\begin{array}{l}\text { No. of H-bridges } \\
\text { and DC sources }\end{array}$} \\
\hline & & Without filter & With filter & \\
\hline 1 & Conventional 7-level Inverter & $10.75 \%$ & NA & 3 \\
\hline 2 & Equal pulse width technique & $23.21 \%$ & $13.04 \%$ & 3 \\
\hline 3 & Unequal pulse width technique & $13.2 \%$ & $6.44 \%$ & 3 \\
\hline 4 & $\begin{array}{l}\text { Phase opposition disposition } \\
\text { technique }(\mathrm{Ma}=1)\end{array}$ & $24.11 \%$ & $2.38 \%$ & 3 \\
\hline 5 & $\begin{array}{l}\text { Phase opposition disposition } \\
\text { technique }(\mathrm{Ma}<1)\end{array}$ & $10.15 \%$ & $1.89 \%$ & 3 \\
\hline
\end{tabular}

\section{Conclusion}

The seven-level CHB-MLI topology with fewer switches is modelled in a Simulink-MATLAB environment using the Phase opposition disposition approach and the suggested topology's functioning with equal and unequal pulses is investigated. The simulation results show that a modulation index of less than one $(\mathrm{Ma}<1)$ gives the appropriate seven-level output wave with a low THD percentage. THD was found to be $10.15 \%$ without a filter and $1.89 \%$ with one.

Future suggestions are as follows:

- The topology may be expanded further by creating a good control design using an improved methodology that takes into account the voltage stress on semiconductor devices.

- By keeping an eye on the voltage stress on the switching devices, the switch count may be lowered.

- With small adjustments to grid side parameters, this architecture might be used for active, reactive power control in grid-tied solar systems.

\section{Acknowledgment}

The authors would like to thank VIT-University Vellore and Vignana Bharathi Institute of Technology-Hyderabad for providing the computational facilities and technical support to carry out this research.

\section{Conflicts of interest}

The authors have no conflicts of interest to declare.

\section{References}

[1] Makhubele JW, Ogudo KA. Analysis on basics of modulation techniques for AC drive on efficiency improvements. In IEEE PES/IAS PowerAfrica 2020 (pp. 1-5). IEEE.

[2] Achary a AB, Ricco M, Sera D, Teoderscu R, Norum LE. Performance analysis of medium-voltage grid integration of $\mathrm{PV}$ plant using modular multilevel converter. IEEE Transactions on Energy Conversion. 2019; 34(4):1731-40.

[3] Zhang X, Wang M, Zhao T, Mao W, Hu Y, Cao R. Topological comparison and analysis of mediumvoltage and high-power direct-linked PV inverter. CES
Transactions on Electrical Machines and Systems. 2019; 3(4):327-34.

[4] Barrios MA, Cárdenas V, Sandoval JM, Guerrero JM, Vasquez JC. A cascaded DC-AC-AC grid-tied converter for PV plants with AC-link. Electronics. 2021; 10(4):1-21.

[5] Latha JH, Banakara BR. Analy sis of multilevel inverter with reduced number of switches fed from photovoltaic system through boost converter. Journal of Critical Reviews. 2020; 7(1):331-6.

[6] Beigi LM, Azli NA, Khosravi F, Najafi E, Kay khosravi A. A new multilevel inverter topology with reduced number of power switches. In international conference on power and energy 2012 (pp. 55-9). IEEE.

[7] Bana PR, Panda KP, Naay agi RT, Siano P, Panda G. Recently developed reduced switch multilevel inverter for renewable energy integration and drives application: topologies, comprehensive analysis and comparative evaluation. IEEE Access. 2019; 7:54888909.

[8] Panda KP, Lee SS, Panda G. Reduced switch cascaded multilevel inverter with new selective harmonic elimination control for standalone renewable energy system. IEEE Transactions on Industry Applications. 2019; 55(6):7561-74.

[9] Siddique MD, Mekhilef S, Shah NM, Sarwar A, Iqbal A, Tayy ab M, et al. Low switching frequency based asymmetrical multilevel inverter topology with reduced switch count. IEEE Access. 2019; 7:86374-83.

[10] Omer P, Kumar J, Surjan BS. A review on reduced switch count multilevel inverter topologies. IEEE Access. 2020; 8:22281-302.

[11] Hosseinpour M, Seifi A, Dejamkhooy A, Sedaghati F. Switch count reduced structure for symmetric bidirectional multilevel inverter based on switch-diodesource cells. IET Power Electronics. 2020; 13(8):167586.

[12] Mondol MH, Tür MR, Biswas SP, Hosain MK, Shuvo S, Hossain E. Compact three phase multilevel inverter for low and medium power photovoltaic systems. IEEE Access. 2020; 8:60824-37.

[13] Kakar S, Ay ob SB, Iqbal A, Nordin NM, Arif MS, Gore S. New asymmetrical modular multilevel inverter topology with reduced number of switches. IEEE Access. 2021; 9:27627-37.

[14] Srinivasan GK, Rivera M, Loganathan V, Ravikumar D, Mohan B. Trends and challenges in multi-level inverter with reduced switches. Electronics. 2021; 10(4):1-23. 
[15] Singh DK, Manna S, Akella AK. Grid connected PV system using multilevel inverter. In 7th international conference on electrical energy systems 2021 (pp. 34651). IEEE.

[16] Sandhu M, Thakur T. Modified cascaded H-bridge multilevel inverter for hybrid renewable energy applications. IETE Journal of Research. 2020.

[17] Narasimhulu V, Kumar DA, Babu CS. Computational intelligence based control of cascaded H-bridge multilevel inverter for shunt active power filter application. Journal of Ambient Intelligence and Humanized Computing. 2020.

[18] Rajalakshmi S, Rangarajan P. Investigation of modified multilevel inverter topology for PV system. Microprocessors and Microsystems. 2019.

[19] Rana RA, Patel SA, Muthusamy A, Kim HJ. Review of multilevel voltage source inverter topologies and analysis of harmonics distortions in FC-MLI. Electronics. 2019; 8(11):1-37.

[20] Zeb K, Khan I, Uddin W, Khan MA, Sathishkumar P, Busarello TD, et al. A review on recent advances and future trends of transformerless inverter structures for single-phase grid-connected photovoltaic systems. Energies. 2018; 11(8):1-34.

[21] Thamilmaran A, Vijay apriy a P, Kowsaly a M. Design of STATCOM using CHB and its comparison with other RPC devices. Indian Journal of Science and Technology. 2016; 9(5):1-7.

[22] Rout KK, Tripathy A, Sahu O, Mishra S. A comparative analysis of different topologies of an eleven level inverter for solar power applications. In international conference on recent innovations in electrical, electronics \& communication engineering 2018 (pp. 140-6). IEEE.

[23] Kumar BS, Kirubakaran A. A single-phase quasi-zsource based seven-level inverter with capacitor voltage balancing. In India international conference on power electronics (IICPE) 2018 (pp. 1-5). IEEE.

[24] Ranjan AK, Bhaskar DV, Parida N. Analysis and simulation of cascaded H-bridge multi level inverter using level-shift PWM technique. In international conference on circuits, power and computing technologies 2015 (pp. 1-5). IEEE.

[25] Udakhe P, Atkar D, Chiriki S, Borghate VB. Comparison of different ty pes of SPWM techniques for three phase seven level cascaded H-Bridge inverter. In 1st international conference on power electronics, intelligent control and energy systems 2016 (pp. 1-5). IEEE.

[26] Alaas Z, Wang C. A new isolated multilevel inverter based on cascaded three-phase converter blocks. In transportation electrification conference and expo 2015 (pp. 1-6). IEEE.

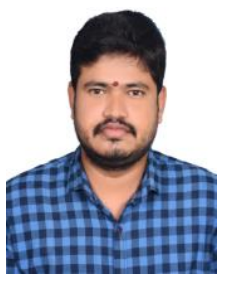

J. N. Bhanutej pursuing his Ph.D in School of Electrical Engineering (SELECT) VIT-Vellore and working as Assistant Professor in the department of Electrical and Electronics Engineering at Vignana Bharathi Institute of Technology (VBIT). His research area is Multilevel Inverters for Renewable

Energy Sources.

Email: bhanutej.mtech@gmail.com

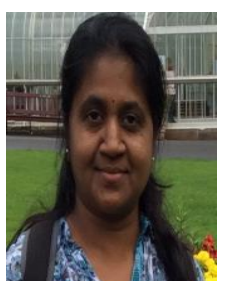

Rani Chinnappa Naidu received the Ph.D. degree in 2014 from the Northumbria University, UK. After that, she joined also Postdoctoral Researcher in Northumbria Photovoltaic Applications Centre at the Northumbria University, UK. She was graduated with a First-Class BEng andMTech in Electrical Engineering both from the VIT University, India. At present, she is working as Associate Professor in VIT University, India. She is a senior member of IEEE. She leads an appreciable number of research groups and projects in the areas such as Solar Photovoltaic, Wind Energy, Power Generation Dispatch, Power System Optimization and Artificial Intelligence Techniques.

Email: crani@vit.ac.in 